\title{
Analytical psychodrama with college students suffering from mental health problems: Preliminary outcomes
}

\author{
Roberta Biolcati, ${ }^{1}$ Francesca Agostini, ${ }^{2}$ Giacomo Mancini ${ }^{1}$ \\ ${ }^{1}$ Department of Education, Alma Mater Studiorum-University of Bologna; ${ }^{2}$ Department of Psychology, Alma Mater Studiorum- \\ University of Bologna, Italy
}

\begin{abstract}
The aim of this work was to assess the therapeutic efficacy of analytical psychodrama groups for college students with psychological problems. Analytical psychodrama, as a form of group psychotherapy, is an integral part of the program of treatment of young adults in the Counselling Center of the University of Bologna, which provides a free service for its students, aimed at delivering psychological support. Thirty patients ( 22 females) from 20 to 26 years old (mean age 22.33, standard deviation \pm 1.75 ), suffering from mental health problems, who completed one year of psychodrama, were assessed before and after group psychotherapy. The Italian validation of Clinical Outcomes in Routine Evaluation - Outcome Measure was used as test-retest questionnaire for clinical outcome evaluation. The results demonstrated the efficacy of the treatment in terms of symptom decrease and improvement of patients' well being. After the treatment (40 sessions, once a week), patients showed a statistically significant reduction in clinical outcomes scores compared with pre-treatment scores. Moreover, the analyses of Reliable and Clinical Significant Change index showed that about $30 \%$ of patients improved, and this improvement was reliable and/or clinically significant. Our preliminary findings revealed that analytical psychodrama is a suitable treatment for college students, as it actually reduces young adults' symptoms. These results contribute to the topic of the validity of psychodrama interventions to encourage research regarding the specific psychotherapeutic effects of its method.
\end{abstract}

Key words: Analytical psychodrama; Clinical outcomes evaluation; College students; Mental health problems.

Correspondence: Roberta Biolcati, Department of Education, Alma Mater Studiorum-University of Bologna, via Filippo Re 6, 40126 Bologna, Italy.

E-mail: r.biolcati@unibo.it

Citation: Biolcati, R., Agostini, F., \& Mancini, G. (2017). Analytical psychodrama with college students suffering from mental health problems: preliminary outcomes. Research in Psychotherapy: Psychopathology, Process and Outcome, 20(3), 201-209. doi: 10.4081/ripppo.2017.272

Contributions: RB conceived, designed the study and wrote the initial draft of the paper. FA and GM contributed to the method of the study and data analysis. All authors contributed to the theoretical discussion of the paper; all authors contributed to read and approved the final manuscript.

Conflict of interest: the authors declare no potential conflict of interest.

Received for publication: 3 May 2017.

Revision received: 6 July 2017.

Accepted for publication: 6 July 2017.

This work is licensed under a Creative Commons Attribution NonCommercial 4.0 License (CC BY-NC 4.0).

CCopyright R. Biolcati et al., 2017

Licensee PAGEPress, Italy

Research in Psychotherapy:

Psychopathology, Process and Outcome 2017; 20:201-209

doi:10.4081/ripppo.2017.272

\section{Introduction}

Young adulthood is characterized by the search for educational opportunities and employment perspectives, and for the development of close relationships. For some individuals, these increased opportunities may result in stress that precipitates the onset or recurrence of mental health problems (Blanco et al., 2008). In addition to stress related to academic performances, college students may have to cope with the task of taking more responsibilities without having yet mastered the skills of adulthood. Instead, many young adults may face stressful circumstances for the first time including being in a significant relationship, working, or comparing opinions with belief systems different from their own (Arnett, 2000). The sense of identity is steadily reshaping in young adulthood (Kroger, 2015). For these reasons, some college students may experience the first onset or the exacerbation of previous mental health problems. Anxiety and mood disorders are the most common difficulties experienced in this population (Pedrelli, Nyer, Yeung, Zulauf, \& Wilens, 2015). Indeed, previous studies report that anxiety disorders afflict approximately $11.9 \%$ of young adults (Blanco et al., 2008), and prevalence rates of depression in college students are estimated between 7 and 9\% (Eisenberg, Hunt, \& Speer, 2013; Zisook \& Kendler, 2007). Along with the increasing awareness and recognition of young adult mental health issues, the rate of university students with mental health problems entering the college has sig- 
nificantly increased; at the same time, there is an increase in demand for counselling and specialized services (Auerbach et al., 2015).

University counselling services have the unique opportunity to readily take care of the psychological problems of university students and consequently prevent their severe consequences (Stallman, 2012). From 1985 up to now, the University of Bologna in Italy has been providing a free counselling service for university students, aimed at delivering psychological support. This service provides a four-session psychological consultation for all university students who are seeking help. The psychotherapist who carried out the consultation presents the case to all the psychotherapists of the staff during a weekly casediscussion meeting, and evaluates whether the initial four sessions are sufficient to solve the psychological problem or whether psychotherapeutic treatment is necessary. During the staff meeting psychotherapists formulate a diagnostic assessment for each patient presented. If the patient needs further intervention, the psychotherapist, supported by the staff, decides which treatment is more tailored: individual or group interventions following a psychodynamic or cognitive-behavioral approach (Monti, Tonetti, \& Ricci Bitti, 2013b).

Among the group treatments offered by the counselling service, analytical psychodrama is a specific form of group psychotherapy psychoanalytically oriented.

The Counselling Centre only recently implemented a procedure to assess the effectiveness of the provided treatments, highlighting a significant improvement in the students' psychological well being at the end of individual psychotherapy, whether psychodynamic or cognitive-behavioral (Monti, Tonetti, \& Ricci Bitti, 2013a; Monti, Tonetti, \& Ricci Bitti, 2015). To date, the effectiveness of analytical psychodrama with college students has never been properly assessed. Generally, group psychotherapy treatments are acknowledged to be efficient clinical interventions (e.g., Burlingame, Strauss, \& Joyce, 2013) and are appreciated for their favorable cost-benefit ratio. In Italy, many specialized public centers provide group psychotherapy (Lo Verso \& Di Blasi, 2011). Despite this, there is still a wide gap between empirical research and psychotherapy clinical practice. In particular, psychodynamic oriented clinicians in the past considered the research activities invasive in their work setting. However, the number of studies on outcome evaluation of group psychotherapy is increasing (Giannone, Giordano, \& Di Blasi, 2015; Gullo, Lo Coco, Prestano, Giannone, \& Lo Verso, 2010; Lo Coco, Prestano, \& Lo Verso, 2008) and also in the practice of psychodrama the evaluation of the clinical outcomes is an emerging issue.

Psychodrama has been developed as a form of group psychotherapy for almost 80 years (Blatner, 2007; see review by Drakulić, 2014). As a form of treatment (conceived by Moreno in the early 1920s), it stems from the discovery that staging one's own conflicts helps to express inhibited feelings (Moreno, 1985). Today, modern analytical psychodrama operates in respect to Moreno's tradition of role-playing games, relying on an analytical perspective. Specifically, the theoretical paradigm of analytical psychodrama has been described and discussed by French child psychoanalysts such as Serge Lebovici or Rene Diatkin. Since 1945, they have been looking for the most appropriate therapeutic techniques for shorter or longer treatment, which would involve the psychoanalytic approach (Tomac et al., 2013). Based on their understanding that expressing oneself through scenic play can produce significant therapeutic effects, after several years of work, while maintaining some technical principles of classic psychodrama (role- and reversal-playing), they created the theory of analytic psychodrama. As a new therapeutic technique, analytical psychodrama has been applied since 1956 in France. While at first it was applied in psychopedagogic centers for the rehabilitation of children and adolescents with a variety of problems (Anzieu, 1979), later it was proved to be successful for several psychopathological symptoms among children, adolescents and adults (Lemoine \& Lemoine, 1973) and its practice has spread also in Italy (e.g., Croce, 2001; Miglietta, 1998). Indeed, analytical psychodrama is a suitable psychotherapy technique for the treatment of anxiety-depressive disorders, borderline and pre-psychotic conditions (Kipper \& Ritchie, 2003). Psychodrama simultaneously works to both raise awareness of suffering mental content and to create more functional models of behavior and communication through the help of the group.

Specifically, in the case of university students, analytical psychodrama can be seen as a suitable treatment considering: the need to consolidate the difficult process of emancipation from the family started in adolescence; the need to become protagonist of their own life, building personal identity and self-esteem; the opportunity of looking at the past and present, and planning the future, overcoming rigid defensive schemes that have led to psychological suffering.

Analytical psychodrama has shown the potential for obtaining positive change in-group members and is reputed as an effective form of psychotherapy (Kipper \& Ritchie, 2003). Nevertheless, as practitioners of psychodrama, we are aware of the contradiction between the favorable clinical impression of the method on the one hand and the lack of empirical validation for its multifarious interventions on the other. There are some case studies published in journals and monographs of various psychodrama associations, but most of the research findings are not published in peer-review journals and the majority of the studies have been published prior to 1980 (Kipper \& Hundal, 2003; McVea, 2004). Indeed, a recent review of the literature (Chung, 2013) highlighted that, before the new century, psychodrama practitioners and researchers had largely ignored evaluating outcomes and reporting empirical evidence about them. Scholars 
(Treadwell \& Kumar, 2002) highlighted that the paucity of scientifically rigorous psychodrama research published in peer-reviewed journals has contributed to its low visibility amongst contemporary psychotherapy approaches.

In addition, to date, there seem to be no publications specifically concerning the use of analytical psychodrama to treat mental health disorders in college students. Only recently, some studies on the empirical validation of psychodrama with an analytic perspective are beginning to appear in international literature. For example, a study by the Gatta research group (Gatta et al., 2010) assessed the use of analytical psychodrama for the treatment of groups of adolescents with psychiatric disorders and showed the efficacy of the treatment in terms of symptoms reduction.

For the aforementioned reasons, the present study was carried out in order to contribute to the development of the literature on analytical psychodrama; in particular, the study aimed at exploring the decrease of symptomatology and the improvement of patients' well-being after analytical psychodrama intervention among college students who asked for help to the Counselling Centre of the University of Bologna. Specifically, we hypothesized that, after 40 sessions of treatment, patients would show significant reductions on clinical outcomes scores compared with pre-treatment scores.

\section{Methods}

Analytical psychodrama is today an integral part of the program of treatment for young adults (18-28 years) delivered by the Counselling Center of the Department of Psychology, Alma Mater Studiorum-University of Bologna.

\section{Setting}

The psychotherapy is conducted by a psychodramatist with a specialization in group psychotherapy at the COIRAG (Confederations of Italian Organizations for Analytical Research on Groups), and member training and supervising of the Italian Society of Analytical Psychodrama (SIPsA). Two psychologists during their training period also attend sessions as Auxiliary Egos. The auxiliary ego is a person who plays a role representing a significant other in the protagonist's life and he is a therapeutic agent of the therapist (Karp \& Farrall, 2014). They do not speak in the group if not involved by the protagonist who is playing a role.

The group usually involves 8-10 members of both genders and the duration of intervention is one year, with weekly 90 min long sessions, except in August, at Christmas, and at Easter. In total, each treatment includes about 40 sessions.

\section{Inclusion and exclusion criteria}

The criteria used to allocate the students to the analytical psychodrama treatment versus other kinds of in- tervention were similar to those used for an individual psychodynamic therapy namely adequate insight, a minimal emotional willingness to collaborate with the therapist and the desire to understand the unconscious reasons for their psychological suffering. The patients needed to be not driven only by the urgency to solve the symptoms (Monti et al., 2013a; Monti, Tonetti, \& Ricci Bitti, 2014). The only patients contraindicated for psychodrama are those who have paranoid ideas or who reject the group therapy.

\section{Working method}

The work method in analytic psychodrama is mainly based on free associations, role-playing and reversal-playing, through which each group member presents specific problems, interpersonal difficulties, so as to reveal his inner conflicts, understand his system of relations, and clarify the patterns of behavior. Unlike the classic technique of Moreno, participants never play desirable scenes; the scenes enacted in an analytical psychodrama are based on specific real events in a person's life, on their current or past relationships, on their inner thoughts and conflicts. And unlike the more traditional psychodrama, the analytic one does not have a cathartic purpose, but a transformative goal, because it enables the participant, through verbal action and enactment, to reconstruct his experiences, in the framework of the group, via the mirroring provided by the group members and the therapist's analytic interventions. In addition, through the group activity in psychodrama, the participant has the opportunity of experiencing a corrective affective experience of the original event, thus changing his perspective on it, and possibly finding alternatives for coping (Vaxberg, 2014).

In summary, psychodrama should help college students to better understand themselves and their history, improve their relationships, express and integrate blocked thoughts and emotions, practice new roles and prepare for the future.

\section{Participants}

The study group consisted of 30 patients from 20 to 26 years old $($ mean $=22.33, \mathrm{SD}=1.75), 22$ females $(73.3 \%)$ and 8 males $(26.7 \%)$ who completed one full year of analytical psychodrama at the Counselling Center of the University of Bologna, in the period from January 2013 to December 2016. All these patients returned complete data on test-retest questionnaires for the clinical outcome evaluation. Three patients who dropped out before the end of the psychotherapy and 2 who provided incomplete data to the re-test were excluded from the evaluation study.

As regards the city of origin, 19 patients $(63.3 \%)$ came from the north, $6(20 \%)$ from the center and $5(16.7 \%)$ from the south of Italy. Fifteen undergraduate students (50\%) were attending the 1st Cycle Degree, and 15 (50\%) the 2nd Cycle Degree or a five-year Degree. 


\section{Tools}

In order to make the diagnostic assessment, the Counselling Center of the University of Bologna has standardized the use of two tools: at the end of a four-session psychological consultation, the Italian translation of the Global Assessment Scale (GAS) (Endicott, Spitzer, Fleiss, $\&$ Cohen, 1976) is used by the psychologist to measure the functioning of an individual at psychological, social and occupational levels. GAS values range between 1 and 100 , divided into ten-point intervals, with higher scores corresponding to a better functioning. The reliability of the GAS has been previously documented (Sohlberg, 1989). Also, the primary diagnosis for each patient is established by referring to the diagnostic classification of the International Classification of Diseases, Ninth Revision (ICD-9-CM; World Health Organization, 1978).

In order to assess the effectiveness of the psychological treatment, every psychotherapist working at the Counselling Centre uses the Clinical Outcomes in Routine Evaluation - Outcome Measure (CORE-OM) (Barkham, Gilbert, Connell, Marshall, \& Twigg, 2005; Evans et al., 2002; Italian validation by Palmieri et al., 2009), a 34item self-report measure designed to assess the level of psychological distress and outcome of the psychological therapy. The CORE-OM is a reliable, valid and sensitive to change instrument to use in clinical audit and it is a recommended outcome measure in Italian psychotherapy services for implementing routine evaluation. The COREOM questionnaire provides scores on 4 domains: Subjective wellbeing (feelings about self and optimism about the future) (4 items), Problems/symptoms (depression, anxiety, physical problems, trauma) (12 items), Functioning (general day-to-day functioning, close relationships, social relationships) (12 items), Risk (risk to self, risk to others) (6 items). In addition, the CORE-OM provides 2 total scores: Non-risk items (28 items); All items (34 items) $(\alpha=.77)$. All items are scored on a five-point scale from 0 to 4 (anchored all or most of the time, not at all, only occasionally, often, and sometimes) and relate to the previous week. Some items are directed at lower and some at higher intensity of problems, with the aim to increase sensitivity to change (Evans et al., 2002); $25 \%$ of the items are reversed scores. All the measures are problem scored, so that higher scores correspond to more severe problems. The original validation and Italian version also report cutoff values (for the 4 dimensions and 2 total scales) both for men and women, in order to distinguish between clinical and non-clinical range (Evans et al., 2002; Palmieri et al., 2009). The reliability of the Italian version of CORE-OM has been reported as showing high internal consistency $(\alpha=0.92)$ (Palmieri et al., 2009). The COREOM Italian version was previously used to investigate the severity of the psychopathology of Italian college students receiving counselling services (Strepparava et al., 2017).

Regarding the use of CORE-OM for our study, the tool was administrated by the psychotherapist (and com- piled by the patient) before and at the end of the therapy. More precisely, the second and second-to-last group psychotherapy sessions.

\section{Statistical analysis}

Data were first analysed in order to describe the main demographics and clinical characteristics of the sample. Univariate ANOVAs were run in order to investigate if specific demographics influenced CORE-OM mean scores, both pre and post-treatment. The variables considered were: gender, provenience (divided into: North, Center, South Italy) and Degree Cycle (divided into: 1st Cycle Degree $v s$ 2nd Cycle Degree or a five-year Degree).

The influence of specific clinical variables (GAS classification and ICD-9 diagnosis) on CORE-OM scores was not considered because of the limited number of the sample when considering the fragmentation into the levels of these variables.

Pre-treatment CORE-OM mean scores were compared with mean scores from the Italian validation study by Palmieri and colleagues (2009) in order to check for similarity between the two clinical samples.

For the main aim of the study, pre and post-treatment CORE-OM mean scores were compared using paired $t$ test, allowing the calculation of group mean change.

Also, specific analyses were conducted in order to complement and extend grouped analyses (Evans, Margison, \& Barkham, 1998), specifically the reliable and clinically significant change (RCSC) was calculated. The RCSC demonstrates how much, and in what direction an individual has changed, and whether that change is reliable (large enough not to be attributable to measurement error) and clinically significant (moving from above a clinical cut-off value to under that value). In fact, reliable change index is that found only in 5\% of cases if change were simply due to unreliability of measurement. Clinically significant change is what moves a person from a score most characteristic of a clinical population to a score more typical of a non-clinical population (Jacobson \& Truax, 1991; Evans et al., 2002). To calculate the RCSC index we followed the methodology used in the original validation (Evans et al., 2002) and the Italian validation of CORE-OM (Palmieri et al., 2009). Based on the Reliable Change index reported in the Italian validation of CORE-OM (Palmieri et al., 2009), 3 possible categories for each individual score were identified: not reliable, reliable improvement, reliable deterioration.

Also, based on the cut-off values for each dimension reported in the Italian version of CORE-OM by Palmieri and colleagues (2009), the clinically significant change of each individual between pre and post-treatment could be classified as: remained in the same clinical range (always above cut-off value); remained in the same non-clinical range (always under cut-off value); changed from clinical to non-clinical range, which means improvement (going from above to under cut-off value); changed from non- 
clinical to clinical range, which represents deterioration (going from under to above cut-off value).

All the data were analysed using the IBMSPSS statistical package version 21.0.

\section{Results}

\section{Clinical characteristics of the sample}

As regards the general functioning at psychological, social and occupational levels, almost all participants (93.3\%) were classified in the GAS range moderate symptoms (60-51), 3.3\% in the range mild symptoms (70-61), and $3.3 \%$ with severe symptoms (50-41). As regards the specific evaluation value, the mean score was 54.33 $(\mathrm{SD}=2.48)$, min- $\max =50-62$.

The diagnoses formulated at the beginning of the treatment referring to the ICD-9 are summarized in Table 1. The most frequent category of diagnosis was represented by neurotic disorders (43.3\%), followed by emotional disorders (33.3\%).

\section{Clinical Outcomes in Routine Evaluation - Outcome Measure and demographic variables of the sample}

Pre-treatment mean scores were not significantly influenced by gender and provenience (all $\mathrm{P}$ values $>0.05$ ). As regards the Cycle of degree, students attending the $1^{\text {st }}$
Cycle exhibited a lower mean score in the Functioning scale compared to the other group (2.14 vs $1.68 ; \mathrm{P}=0.05)$.

Post-intervention mean scores proved to be significantly influenced by the above mentioned variables. Specifically, concerning gender differences, women showed a lower mean score in the Functioning scale compared to that of men (1.58 vs 2.33; $\mathrm{P}=0.033)$. Also, students coming from the South of Italy showed a significant lower mean score in the Functioning scale compared to the students coming from the North of Italy (1.62 vs 1.91; $\mathrm{P}=0.047$ ). Regarding the Degree Cycle, students attending the $1^{\text {st }}$ Cycle showed a significant lower mean score in the Functioning scale, compared to the mean scores for students attending the $2^{\text {nd }}$ Cycle or a five years degree, (1.47 vs 2.09; $\mathrm{P}=0.043$ ).

\section{Clinical Outcomes in Routine Evaluation - Outcome Measure pre- and post-treatment}

Pre-treatment mean scores for each CORE-OM scale were initially compared with the values from the clinical sample of the Italian validation of the same instrument. Most of the scales, except for one (Risk scale), showed a mean score not significantly different from the Italian validation sample (Table 2).

Pre-treatment mean scores for every CORE-OM scale were compared with post-treatment ones. Paired $t$ tests showed significant differences for most of the scales, ex-

Table 1. International Classification of Diseases, Ninth Revision, diagnostic categories.

\begin{tabular}{lcc}
\hline & $\mathbf{N}$ & $\mathbf{\%}$ \\
\hline 300. Neurotic disorders (anxiety, hysteria, phobia, obsessive-compulsive disorder, somatization, etc.) & 13 & 43.3 \\
\hline 301. Personality disorders (affective personality disorder, narcissistic personality, dependent personality disorder, etc.) & 2 & 6.7 \\
\hline 309. Adaptive reactions (brief depressive reaction, prolonged depressive reaction, etc.) & 5 & 16.7 \\
\hline 313. Emotional disorders (overanxious disorder, hypersensitivity, shyness, social isolation, relationship problems, etc.) & 10 & 33.3 \\
\hline Total & 100 \\
\hline
\end{tabular}

Table 2. Means scores and standard deviations for Palmieri's and our clinical samples (pre-treatment) on Clinical Outcomes in Routine Evaluation - Outcome Measure scales.

\begin{tabular}{lccc}
\hline Domain & $\begin{array}{c}\text { Clinical } \\
\text { Sample } \\
\mathbf{( n = 3 0 )}\end{array}$ & $\begin{array}{c}\text { Clinical } \\
\text { Italian sample } \\
\mathbf{( n = 6 3 9 )} \\
(\text { Palmieri et al., 2009) }\end{array}$ & P \\
\hline Well-being & $2.35(0.81)$ & $2.31(0.97)$ & 0.79 \\
\hline Symptoms & $2.07(0.63)$ & $1.89(0.85)$ & 0.12 \\
\hline Functioning & $1.88(0.73)$ & $1.64(0.67)$ & 0.08 \\
\hline Risk & $0.55(0.56)$ & $0.41(0.62)$ & $0.0005^{*}$ \\
\hline Non-risk items & $2.03(0.56)$ & $1.84(0.71)$ & 0.07 \\
\hline All items & $1.77(0.53)$ & $1.59(0.66)$ & 0.07
\end{tabular}

Values are expressed as means (standard deviation). 
cept for Functioning and Risk domains: post-mean scores were always significantly lower than pre-intervention values (Table 3).

We then looked at the number of participants falling within the categories established on the basis of the RCSC index. Table 4 shows 9 possible categories with the observed frequencies of subjects we found.

The number of participants who showed both a reliable and clinically significant change was 7 , that is corresponding to $23.3 \%$ of the total sample, which means that for 7 students there was a reliable change and at the same time a significant clinical improvement. Moreover, 1 student showed a clinical significant improvement (score moving under the cut-off value), even if there was not a sufficiently reliable change; also, 2 participants showed a reliable improvement in their scores, even if these did not move from above to under the cut-off value.

\section{Discussion}

To our knowledge, the present study is the one of the first exploring the decrease of clinical outcomes after one year of analytical psychodrama intervention among college students suffering for mental health problems. Based on the lack of studies on this topic, our results are promising and may contribute to the increase of the literature.
In our sample, as regards the initial general functioning at psychological, social and occupational levels, college students were located in the GAS range Moderate symptoms (60-51): generally functioning with some difficulties (e.g., few friends and flat affect, depressed mood and pathological doubt, euphoric mood and pressure of speech, moderately severe antisocial behavior) (Endicott et al., 1976). As expected, the diagnosis most represented was in the anxiety-depression spectrum (neurotic disorders, adaptive reactions and emotional disorders). Substantially, our sample showed a CORE-OM mean score not significantly different from the Italian validation sample (Palmieri et al., 2009). As regards the Clinical Outcomes at the baseline, participants obtained highest scores in the Well-being and Symptoms scales, thus showing a greater suffering in these two domains.

After one year of analytical psychodrama intervention, our results showed a statistically significant decrease on CORE-OM total scores, meaning a substantial improvement in the patient's well-being. Specifically, the scores on the Well-being and Problems/Symptoms domains were considerably reduced in the post-test. On average, Functioning and Risk scores decrease in the post-test, even if the differences between pre- and post-treatment are not statistically significant. Note that in the pre-test the Functioning average score (1.88) is located below the middle of the rating scale (0-4) and the average of the risk scale $(0.55)$ is generally very low. Patients who scored very low

Table 3. Pre and post-treatment Clinical Outcomes in Routine Evaluation - Outcome Measure mean scores.

\begin{tabular}{llcc}
\hline Domain & $\begin{array}{c}\text { CORE-OM } \\
\text { Pre-test } \\
\mathbf{( n = 3 0 )}\end{array}$ & $\begin{array}{c}\text { CORE-OM } \\
\text { Post-test } \\
(\mathbf{n}=\mathbf{3 0})\end{array}$ & P \\
\hline Well-being & $2.35(0.81)$ & $1.94(0.78)$ & 0.026 \\
\hline Symptoms & $2.07(0.63)$ & $1.63(0.62)$ & 0.0005 \\
\hline Functioning & $1.88(0.73)$ & $1.78(0.85)$ & 0.40 \\
\hline Risk & $0.55(0.55)$ & $0.47(0.48)$ & 0.28 \\
\hline Non-risk items & $2.03(0.56)$ & $1.73(0.65)$ & 0.005 \\
\hline All items & $1.77(0.52)$ & $1.51(0.61)$ & 0.006 \\
\hline
\end{tabular}

Values are expressed as means (standard deviation).

Table 4. Reliable and clinically significant change.

\begin{tabular}{lcccc}
\hline Clinically significant change & Reliable deterioration \\
$\mathbf{N}(\mathbf{\%})$ & $\begin{array}{c}\text { No reliable change } \\
\mathbf{N}(\mathbf{\%})\end{array}$ & $\begin{array}{c}\text { Reliable improvement } \\
\mathbf{N}(\mathbf{\%})\end{array}$ & Total \\
\hline Clinically significant deterioration & 0 & 0 & 0 & 0 \\
\hline No clinically significant change & 0 & $20(90.9)$ & $2(9.1)$ & $22(100)$ \\
\hline Clinically significant improvement & 0 & $1(13.5)$ & $7(87.5)$ & $8(100)$ \\
\hline Total & 0 & $21(70)$ & $9(30)$ & 30 \\
\hline
\end{tabular}

Reliable and clinically significant change shown in italics. 
on entry to therapy tend to show less clinically significant improvement (Evans et al., 2002).

Therefore, psychodrama intervention seemed to be effective, leading to a decrease of symptomatology and to an improvement of the patients' well-being. Our findings show that analytical psychodrama, while not working directly on the symptoms but on the underlying meanings to them, allows a significant reduction in anxiety-depressive symptomatology and a substantial decrease of the subjectively experienced discomfort. In accordance with Cohen (1988), we might say that the analytical psychodrama significantly reduced clinical outcomes to a sizeable degree in college students.

In general, a statistical significance, based on the means of the groups, leads clinicians to conclude that such an extreme difference in unlikely to be due to change (Field, 2006). Nevertheless, from a clinical point of view, it would be useful to know if the individual change is clinically significant, which is the reason why we calculated the RCSC index. The effect is defined as clinically significant if the individual has moved from being more like a clinical population (for example, affected by a neurotic disorder) to being more like a non-clinical comparison population (non affected by a neurotic disorder). Furthermore, the change is reliable if the difference between pre and post scores has taken into account the reliability of the measure used (Zahra \& Hedge, 2010).

In our study, 7 patients $(23.3 \%$ of the total) showed the ideal outcome on RCSC, namely a reliable and clinically significant improvement (in other words the total recovery); 3 patients (10\%) showed an improvement (reliable or clinically significant); 20 patients $(66.6 \%)$ remained stable (even if there was an individual change, this was not considered as reliable and/or clinically significant), and no one showed either clinical significance or reliable deterioration.

As regards the RCSC index analyses, some important considerations need to be done. First, Evans and co-workers (2002) argued that a few patients will score too low on entry into therapy to show clinically significant improvement, whereas some will score highly on entry and improve reliably but will not necessarily go below the cutoff, so they will not show a clinically significant improvement. Additionally, the return to normal condition, namely the definition of RCSC, seems unrealistic for many clinical practice contexts (Jacobson \& Revenstorf, 1988). For example, meta-analytical studies of outpatients with depression report that few achieve complete remission and, despite significant improvements, some data indicate that many of these patients remain more depressed at the end of therapy than the general population (e.g., Westen \& Morrison, 2001). In addition, a return to normal functioning may be expected to take considerably longer than symptom remission, and it is unclear if particular functional impairments remit slower than others (e.g., increased socialization). For these reasons, the return to normal criterion appears sometimes unrealistic because, in general, only few patients reach a full remission of depressive symptoms, and functional capacities are the last improvements (Wise, 2004).

Despite these considerations, the analyses of the RCSC index in our patients showed that not only did about $30 \%$ of the patients improve, but this improvement was also reliable and/or clinically significant. This result seems important to support our results on the effectiveness of analytical psychodrama but, above all, it allows to reason on each patient's specific characteristics and his/her greater or lesser positive response to the psychotherapy.

\section{Conclusions}

Concluding, this exploratory research contributed to a topic poorly covered in the international literature, namely the issue of the therapeutic value of analytical psychodrama to treat college students' mental health problems. Our preliminary findings revealed that this form of group psychotherapy was effective in reducing young adults' symptoms, specifically anxiety-depressive symptoms were significantly lower after the psychodrama intervention. We have to take into consideration some limitations, which could have influenced the results: we did not include a comparison with a control group, and we also did not include any follow-up assessment.

In any case, the preliminary findings appear to contribute to the issue of the effectiveness of analytical psychodrama interventions sufficiently to encourage future research regarding the specific psychotherapeutic effects of this method. Specifically, future research on the therapeutic effectiveness of analytical psychodrama for the treatment of mental health disorders in college students should at least address the following directions: a longterm follow-up; a comparison of analytic psychodrama treatment with other forms of group psychotherapy; a qualitative study of the group dynamic during the sessions, and an in-depth analysis of the role-playing games and their meanings.

\section{References}

Anzieu, D. (1979). Lo psicodramma analitico del bambino e dell'adolescente. Rome, Italy: Astrolabio.

Arnett, J.J. (2000). Emerging adulthood. A theory of development from the late teens through the twenties. American Psychologist, 55, 469-80. doi:10.1037/0003-066X.55.5.469

Auerbach, R.P., Alonso, J., Axinn, W.G., Cuijpers, P., Ebert, D.D., Green, J. G., ..., \& Nock, M.K. (2016). Mental disorders among college students in the World Health Organization, World Mental Health Surveys. Psychological Medicine, 46, 1-16. doi:10.1017/S0033291716001665

Barkham, M., Gilbert, N., Connell, J., Marshall, C., \& Twigg, E. (2005). Suitability and utility of the CORE-OM and CORE-A for assessing severity of presenting problems in psychological therapy services based in primary and sec- 
ondary care settings. The British Journal of Psychiatry, 186(3), 239-246. doi:10.1192/bjp.186.3.239

Blanco, C., Okuda, M., Wright, C., Hasin, D.S., Grant, B.F., Liu, S.M., \& Olfson, M. (2008). Mental health of college students and their non-college-attending peers: results from the national epidemiologic study on alcohol and related conditions. Archives of General Psychiatry, 65(12), 1429-1437. doi: 10.1001/archpsyc.65.12.1429

Blatner, A. (2007). Meta-theoretical perspectives on psychodrama. In C. Baim, J. Burmeister, \& M. Maciel (Eds.), Psychodrama: advances in theory and practice (pp. 5-20). London: Routledge.

Burlingame, G.M., Strauss, B., \& Joyce, A. (2013). Change mechanisms and effectiveness of small group treatments. In M.J. Lambert (Ed.), Bergin and Garfield's handbook of psychotherapy and behavior change (pp. 640-689). London: Sage Publications Inc.

Chung, S.F. (2013). A review of psychodrama and group process. International Journal of Social Work and Human Services Practice, 1(2), 105-114. doi:10.13189/ijrh.2013.010204

Cohen, J. (1988). Statistical power analysis for the behavioural sciences, $2^{\text {nd }}$ ed. Hillsdale, NJ: Lawrence Erlbaum Associates.

Croce, E.B. (2001). La realtà in gioco. Reale e realtà in psicodramma analitico. Rome, Italy: Borla.

Drakulić, A.M. (2014). Critical reflections for understanding the complexity of psychodramatic theory. Psychiatria Danubina, 26(1), 12-19.

Eisenberg, D., Hunt, J., \& Speer, N. (2013). Mental health in American colleges and universities: variation across student subgroups and across campuses. The Journal of Nervous and Mental Disease, 201(1), 60-67. doi: 10.1097/NMD.0b013 e31827ab077

Endicott, J., Spitzer, R.L., Fleiss, J.L., \& Cohen, J. (1976). The global assessment scale: A procedure for measuring overall severity of psychiatric disturbance. Archives of General Psychiatry, 33(6), 766-771. doi:10.1001/archpsyc.1976. 01770060086012

Evans, C., Connell, J., Barkham, M., Margison, F., McGrath, G., Mellor-Clark, J., \& Audin, K. (2002). Towards a standardised brief outcome measure: psychometric properties and utility of the CORE-OM. The British Journal of Psychiatry, 180(1), 51-60. doi:10.1192/bjp.180.1.51

Evans, C., Margison, F., \& Barkham, M. (1998). The contribution of reliable and clinically significant change methods to evidence-based mental health. Evidence Based Mental Health, 1(3), 70-72. doi:10.1136/ebmh.1.3.70

Field, A.A., \& Wright, D. (2006). Bluffer's guide to effect sizes. Psychology Postgraduate Affairs Group, 58, 9-23.

Gatta, M., Dal Zotto, L., Del Col L., Spoto, A., Testa Costantino, P., Ceranto, G., ..., \& Battistella, P. (2010). Analytical psychodrama with adolescents suffering from psycho-behavioral disorder: Short-term effects on psychiatric symptoms. The Arts in Psychotherapy, 37(3), 240-247. doi: 10.1016/j. aip.2010.04.010

Giannone, F., Giordano, C., \& Di Blasi, M. (2015). Group Psychotherapy in Italy. International Journal of Group Psychotherapy, 65(4), 501-511. doi:10.1521/ijgp.2015.65.4.501

Gullo, S., Lo Coco, G., Prestano, C., Giannone, F., \& Lo Verso, G. (2010). Group therapy research: Current issues and future directions. Ricerca in Psicoterapia/Research in Psychotherapy, 13(2), 78-96. doi:10.4081/ripppo.2010.15

Jacobson, N.S., \& Revenstorf, D. (1988). Statistics for assessing the clinical significance of psychotherapy techniques: Is- sues, problems, and new developments. Behavioral Assessment, 10, 133-145.

Jacobson, N.S., \& Truax, P. (1991). Clinical significance: a statistical approach to defining meaningful change in psychotherapy research. Journal of Consulting and Clinical Psychology, 59(1), 12. doi:10.1037/0022-006X.59.1.12

Karp, M., \& Farrall, M. (2014). An Introduction to Psychodrama Concepts and Terms. In P., Homes, M., Farrall, \& K., Kirk (Eds.). Empowering therapeutic practice: integrating psychodrama into other therapies (p. 9). London, UK: Jessica Kingsley Publishers.

Kipper, D.A., \& Hundal, J. (2003). A survey of clinical reports on the application of psychodrama. Journal of Group Psychotherapy Psychodrama and Sociometry, 55(4), 141-158.

Kipper, D.A., \& Ritchie, T.D. (2003). The effectiveness of psychodramatic techniques: A meta-analysis. Group dynamics, theory, research, and practice, 7(1), 13-25. doi:10.1037/ 1089-2699.7.1.13

Kroger, J. (2015). Identity development through adulthood: The move toward "wholeness". The Oxford handbook of identity development. Editors: K.C. McLean \& M. Syed. Oxford University Press, pp.65-80.

Lemoine, P., \& Lemoine, G. (1973). Lo Psicodramma. Milan: Feltrinelli.

Lo Coco, G., Prestano, C., \& Lo Verso, G. (2008). L'efficacia clinica delle psicoterapie di gruppo. Milan, Italy: Raffaello Cortina.

Lo Verso, G., \& Di Blasi, M. (2011). Gruppoanalisi soggettuale. Milan, Italy: Raffaello Cortina.

McVea, C. (2004). It's not enough just to say it works: research into psychodrama and experiential therapies. Australian and Aotearoa New Zealand Psychodrama Association Journal, 13,42 .

Miglietta, D. (1998). I sentimenti in scena. Lo psicodramma e le sue applicazioni. Turin: UTET.

Monti, F., Tonetti, L., \& Ricci Bitti, P.E. (2013a). Effectiveness of psychological treatments delivered at a counseling service for students. Psychological Reports, 113, 955-968. doi:10.2466/21.02.PR0.113x28z4

Monti, F., Tonetti, L., \& Ricci Bitti, P.E. (2013b). Il Servizio di Aiuto Psicologico (SAP) dell'Università di Bologna. Psicologia Clinica dello Sviluppo, XVII, 147-159. doi:10. 1449/73831

Monti, F., Tonetti, L., \& Ricci Bitti, P.E. (2014). Comparison of cognitive-behavioral therapy and psychodynamic therapy in the treatment of anxiety among university students: An effectiveness study. British Journal of Guidance \& Counselling, 42, 233-244. doi:10.1080/03069885.2013.878018

Monti, F., Tonetti, L., \& Ricci Bitti, P.E. (2015). Short-term effectiveness of psychotherapy treatments delivered at a university counselling service. British Journal of Guidance \& Counselling, 44, 414-422. doi:10.1080/03069885.2015. 1119233

Moreno, J.L. (1985). Manuale di psicodramma: il teatro come terapia. Rome: Astrolabio.

Palmieri, G., Evans, C., Hansen, V., Brancaleoni, G., Ferrari, S., Porcelli, P., ..., \& Rigatelli, M. (2009). Validation of the Italian version of the clinical outcomes in routine evaluation outcome measure (CORE-OM). Clinical psychology \& psychotherapy, 16(5), 444-449. doi:10.1002/cpp.646

Pedrelli, P., Nyer, M., Yeung, A., Zulauf, C., \& Wilens, T. (2015). College students: mental health problems and treatment considerations. Academic Psychiatry, 39(5), 503-511. doi:10.1007/s40596-014-0205-9 
Sohlberg, S. (1989). There's more in a number than you think: New validity data for the global assessment scale. Psychological Reports, 64, 455-461. doi: 10.2466/pr0.1989.64.2.455

Stallman, H.M. (2012). University counselling services in Australia and New Zealand: Activities, changes, and challenges. Australian Psychologist, 47(4), 249-253. doi:10.1111/ j.1742-9544.2011.00023.x

Strepparava, M.G., Bani, M., Zorzi, F., Mazza, U., Barile, F., \& Rezzonico, G. (2017). Does the severity of psychopathology of Italian students receiving counselling services increase over time? A 5-year analysis and a comparison with a clinical and non-clinical sample. Clinical Psychology and Psychotherapy, 2017, 1-7. doi:10.1002/cpp.2096

Tomac, A., Jakovina, T., DeZan, D., Begovac, I., Pleština, S., Maček, I., ..., \& Sabol, F. (2013). Individual and Group Psychoanalytical Psychotherapy through dramatization or Analytical Psychodrama at Department of Psychological Medicine of the School of Medicine, University of Zagreb, University Hospital Center Zagreb. Double, 1, 126-131.

Treadwell, T.W., \& Kumar, V.K. (2002). Introduction to the special issue on cognitive behavioral therapy and psychodrama. Journal of Group Psychotherapy Psychodrama and Sociometry, 55(2-3), 51-54.

Vaxberg, Z. (2014). Influence of Group Therapy in Psychodrama on the Attachment Style of Children at-Risk: Educational,
Emotional, Social, and Behavioral Aspects. Kultura Społeczeństwo Edukacja, 2, 6.

Westen, D., \& Morrison, K. (2001). A multidimensional metaanalysis of treatments of depression, panic and generalized anxiety disorder: An empirical examination of the status of empirically supported therapies. Journal of Consulting \& Clinical Psychology, 69(6): 875-899. doi:10.1037/0022006X.69.6.875

Wise, E.A. (2004). Methods for analyzing psychotherapy outcomes: A review of clinical significance, reliable change, and recommendations for future directions. Journal of Personality Assessment, 82(1), 50-59. doi:10.1207/s15327752 jpa8201_10

World Health Organization (1978). The International classification of diseases: ninth revision, clinical modification (ICD-9-CM). Washington, DC: U.S. Dept. of Health and Human Services, Public Health Service, Health Care Financing Administration.

Zahra, D., \& Hedge, C. (2010). The reliable change index: Why isn't it more popular in academic psychology. Psychology Postgraduate Affairs Group Quarterly, 76(76), 14-19.

Zisook, S., \& Kendler, K.S. (2007). Is bereavement-related depression different than non-bereavement-related depression? Psychological Medicine, 37(06), 779-794. doi:10.1017/ S0033291707009865 